\title{
$\mathcal{A}$ construcão de um $\mathcal{A}$ tlas $\mathcal{L}$ inguístico do Brasil: o percurso do $\mathcal{A} \mathcal{L} i \mathcal{B}$
}

\author{
Jacyra Andrade MOTA* \\ Suzana Alice Marcelino CARDOSO **
}

Resumo: Uma dentre as dificuldades que se interpõem na construção de um atlas linguístico diz respeito ao tempo despendido na execução da obra. Partindo-se de considerações dessa natureza e pensando-se no atlas linguístico do Brasil, algumas questões se põem: Como é fazer-se um atlas de um país continental? Como é lidar com as distâncias numa terra de tamanha amplitude? Como se pode estabelecer um tempo para fazer-se um atlas dessas proporções sem a segurança da continuidade de verbas provindas de um sistema de fomento à pesquisa? O Projeto $\mathrm{ALiB}$, previsto para se desenvolver em quatro grandes etapas, segue princípios metodológicos fixados pelo Comitê Nacional, entre 1996 e 2002, que estabelecem o perfil e o número de informantes, a rede de pontos e os tipos de questionário a serem utilizados na constituição do corpus. Desses critérios dá-se conta, salientando-se o saldo altamente positivo que a construção do $\mathrm{ALiB}$ vem propiciando à Geolinguística no Brasil, particularmente na implementação de inúmeros trabalhos nessa área, o que justifica a proposta de uma quarta fase (CARDOSO; MOTA, 2006) para a história da Dialectologia Brasileira, marcada também pela incorporação de

* Doutorado em Letras (Letras Vernáculas) pela Universidade Federal do Rio de Janeiro (2002). Docente da Universidade Federal da Bahia. Contato: jacymota@ufba.br.

* Doutorado em Letras (Letras Vernáculas) pela Universidade Federal do Rio de Janeiro (2002). Docente da Universidade Federal da Bahia. Contato: suzalice@ufba.br. 
outros parâmetros, além do diatópico, configurando a Dialectologia Pluridimensional.

Palavras-chave: Dialectologia; Geolinguística; Português do Brasil; Metodologia dialetal.

Abstract: One of the difficulties found in the construction of a linguistic atlas is related to the time spent to do it. Considering this difficulty and thinking of a Brazilian linguistic atlas, some questions can be asked: What is it like to prepare an atlas of a continental country? How can we deal with the distances of such a huge territory? How can we establish a deadline to prepare the atlas without being sure whether the funds for the research will be kept or not? The ALiB project is to be developed in four phases and it is in keeping with methodological principles set by the National Committee, between 1996 and 2002, which establish the profile and the number of informants, the network of points and the types of questionnaires that will be used for the corpus. These criteria enhance the positive balance that the construction of the ALiB has given the Geolinguistics in Brazil, especially the implementation of numberless works in this area, what justifies the proposal of a fourth phase (CARDOSO; MOTA, 2006) for the history of the Brazilian Dialectology, which also comprehends other parameters, besides the diatopic one, thus configuring the Multidimensional Dialectology.

Keywords: Dialectology; Geolinguistics; Brazilian Portuguese; Dialectal methodology.

\section{Uma preliminar}

Uma dentre as dificuldades que se interpõem na construção de um atlas linguístico diz respeito ao tempo despendido na execução da obra. O tempo que demanda a programação, o tempo que requer a coleta de dados, o tempo de que se precisa para exegese e análise dos materiais e, por fim, o tempo, muitas vezes longo e indefinido, que se tem a esperar para que se viabilize a publicação. 
Desses "tempos" de espera, necessário se faz destacar o que se despende na identificação de informantes que preencham os requisitos estabelecidos e, assim, venham a integrar o conjunto a ser selecionado. Pode parecer a alguns menos familiarizados na lida com a pesquisa linguística que numa cidade, seja de pequeno ou grande porte, não seria difícil encontrarem-se dois, quatro, seis ou mais informantes rigorosamente dentro dos padrões requeridos pela pesquisa. A realidade tem mostrado, porém, que essa não é tarefa fácil. Se se tenta, por exemplo, manter sob controle naturalidade do informante, naturalidade dos seus pais, tempo e local de residência, natureza de viagens e respectiva duração, grau de escolaridade, a que se juntam idade e gênero, depara-se o pesquisador com dificuldades e imprevistos que, muitas vezes, ultrapassam a sua expectativa ou se apresentam de forma surpreendente no curso da coleta de dados. Nesta situação, encontram-se os casos em que, no decorrer da entrevista, e muitas vezes já muito avançada, o informante se refere a um fato, do qual não tinha sido dado informação no preenchimento da ficha inicial, mas que indica, por exemplo, que viveu muito tempo fora, ou que seus pais chegaram já adultos para a cidade, ou mesmo de um curso, de nível além do estabelecido como critério, feito já depois de adulto. E, nesses casos, a gravação feita fica como experimental, e corre-se à busca de outro informante.

Às dificuldades, como as que se acaba de exemplificar com um caso específico - o do encontro de informantes conforme os critérios estabelecidos -, acrescentam-se outras, não de caráter metodológico ou linguístico stricto sensu, mas de cunho social ou político ou econômico que implicam tempo e somam anos à execução de um atlas. E são vários os exemplos a ilustrar a questão. Dentre tantos, tomam-se duas histórias, uma de fora e outra de dentro do nosso país: a do Atlas Lingüistico de la Península Ibérica (ALPI) (GUARNER; CASTELLANO; OTERO, 1962), pela sua particular trajetória e pelo que representa de informação no capítulo da construção de um atlas linguístico, e a que percorreu o Atlas Lingïistico de Sergipe (ALS) (FERREIRA et al., 1987). 
A história do ALPI começa em 1929, quando se ativam os trabalhos, graças à ação da Junta de Relaciones Culturales e ao empenho de Don Tomás Navarro e Don Menendez Pidal. Iniciamse, assim, em 1931, os inquéritos linguísticos que se realizam até 1936, quando se interrompem em virtude da guerra civil espanhola. Até esse ano, tinham sido recolhidos materiais do leonês, do castelhano, do andaluz, do aragonês e estava avançada a realização dos inquéritos do catalão e do galego.

A guerra civil espanhola motivou uma longa interrupção no andamento do atlas e levou os materiais recolhidos a uma peregrinação por muitas partes. Inicialmente, esse conjunto de dados foi levado a Valência e, a seguir, a Barcelona, sempre sob a guarda do diretor da obra, Don Tomás Navarro. Em 1939, passa o acervo de Barcelona a Paris e mais tarde a Nova York, onde fica depositado na Universidade de Colúmbia, da qual Don Tomás Navarro era professor.

A instalação, em Madrid, do Consejo Superior de Investigaciones Científicas, no ano de 1940, foi muito benéfica para o trabalho dialetal, pois não tardou esse Conselho em decidir pelo apoio à continuidade do ALPI. Dessa forma, retoma-se o trabalho: a equipe de Sanchis Guarner-Moll termina os inquéritos da Catalunha e Rodriguez Castellano, os de Astúrias. Em 1950, esses dois pesquisadores vão a Nova York e recebem do Professor Navarro os materiais do ALPI que voltam à Espanha e ficam depositados no Patronato Menendez y Pelayo do Consejo Superior de Investigaciones Científicas.

O ano de 1953 foi marcado pela entrada de Portugal que, com o apoio do Instituto de Alta Cultura, se incorpora às atividades do ALPI, com realização de inquéritos em quase todo o território português feitos por Luís Felipe Lindley Cintra e Aníbal Otero.

Em 1962, portanto 33 anos depois de iniciado, publica-se em Madrid o Atlas Lingüistico de la Peninsula Ibérica I Fonética, 1, sob a responsabilidade do Consejo Superior de Investigaciones Científicas.

A história do ALS não teve guerra civil no seu caminho, mas percorreu um longo tempo. Iniciados os inquéritos 
experimentais em 1964, a coleta definitiva de dados se deu nos anos de 1966 e 1967. A partir de então, procedeu-se à transcrição dos dados, à análise e exegese dos materiais e à elaboração das cartas, já não mais com o concurso de um desenhista, como sucedeu com o Atlas Prévio dos Falares Baianos (APFB) (ROSSI; ISENSEE; FERREIRA, 1963), mas com a utilização de uma máquina elétrica de esferas removíveis e, consequentemente, substituíveis e passíveis de um processo de alternância que atendesse aos símbolos, sinais e letras de que se precisava.

Concluídos, em 1973, os trabalhos de elaboração das cartas e notas a elas pertinentes e prontos os originais para publicação, esta só vem, porém, a acontecer em 1987, ou seja, 14 anos depois. $\mathrm{E}$ isso se deu não por falta de iniciativa dos responsáveis pelo trabalho na busca de financiamento. Percorreu-se ceca e meca, buscou-se todo tipo de apoio e auxílio, recorreu-se até a uma editora de larga circulação que chegou a receber os materiais, examinouos, mas disse não ser obra que atendesse à sua política de publicação. Certamente, pensamos nós, e a reflexão é de nossa inteira interpretação e responsabilidade, a obra não dava para ser vendida em fascículos em bancas de jornal!

Assim, só em 1987 publica-se o Atlas Lingüistico de Sergipe, graças ao entendimento do trabalho científico dessa natureza que tiveram personalidades como: o Reitor Germano Tabacof e a ViceReitora Eliane Azevedo, da Universidade Federal da Bahia, dos quais se diz nos Agradecimentos (FERREIRA et al., 1987), "dotados de respeito e sensibilidade para com trabalhos lingüísticos, deram à Obra o apoio que lhe faltava para concretizar a publicação", o Presidente do Conselho Estadual de Cultura do Estado de Sergipe, Dr. Luís Fernando Ribeiro Soutello, "o primeiro que decidiu, em Sergipe, que o Atlas deveria ser impresso - decisão que foi a pedra fundamental" (FERREIRA et al., 1987); e os Presidentes da Fundação Estadual de Cultura de Sergipe, Fernando Lins de Carvalho e Núbia do Nascimento Marques, "que dividiram o empenho para tornar o Atlas uma realidade" (FERREIRA et al., 1987). 
A publicação do ALS fez Carlota Ferreira, um de seus autores e de quem partiu a iniciativa da realização do trabalho em Sergipe, exclamar no dia do lançamento da obra: "Sete anos de Pastor Jacob serviu [...] mas para que se publicasse o Atlas foram precisos 14 anos, tamanho o nosso amor pela Dialectologia".

O que se quer, enfim, com essa ênfase dada ao "tempo"? Primeiramente, salientar que a realização de um atlas linguístico requer tempo pela sua especificidade e pelas variáveis que deve, por razões científicas, manter sob controle. Em segundo, porque todo trabalho de pesquisa se insere num contexto social, histórico e político, cujos desdobramentos, no tempo e no espaço, nem sempre são previsíveis e fogem, por outro lado, do controle dos cidadãos, e cujos reflexos se farão sentir, inevitavelmente, no andamento e no sucesso do trabalho científico em realização. E isso foi o que se quis ilustrar, trazendo à memória a história do ALPI e do ALS.

Partindo dessas considerações gerais, e pensando-se no atlas linguístico do Brasil, na mesma linha do tempo e do espaço, algumas questões vêm, de imediato, à tona: Como é fazer-se um atlas de um país continental? Como é lidar com as distâncias numa terra de tamanha amplitude, tendo-se de enfrentar os percalços de locomoção em decorrência do sistema viário? Como é que se pode, enfim, estabelecer um tempo para fazer-se um atlas dessas proporções sem a segurança da continuidade de verbas provindas de um sistema de fomento à pesquisa preocupado em, reconhecendo a validade da atividade de investigação, assegurarlhe a continuidade e a conclusão?

\section{Situando o Projeto ALiB} $\mathrm{ALiB}$

E neste quadro do tempo-espaço busca-se situar o Projeto

Assim, e para começar-se pelo espaço, tomando-se apenas os estados onde as pesquisas de campo já foram integralmente concluídas - Roraima, Amapá, Acre, Alagoas, Sergipe, Mato Grosso do Sul, São Paulo e Paraná -, verifica-se que o corpus constituído 
nestes oito estados representa $29 \%$ do total das localidades que compõem a rede nacional de pontos e corresponde a uma área de $1.368 .285 \mathrm{~km}^{2}$, ou seja, aproximadamente $15 \%$ do território nacional, números estes bastante significativos. Se se estabelece uma relação, por exemplo, com o continente europeu, verifica-se que a área global dos estados com documentação concluída equivale, do ponto de vista areal, aproximadamente, à Itália, Espanha, França, Portugal, Suíça, Áustria e Bélgica, reunidos. Esta singela comparação mostra, do ponto de vista espacial, como se põe a questão de vencer as distâncias para um trabalho em território brasileiro. O pesquisador se desloca do seu ponto sede e, para a realização de inquéritos, pode ultrapassar, com muita facilidade, a casa dos mil quilômetros. Para comprovar a veracidade da informação, vejam-se dados da pesquisa referentes, especificamente, aos começos de 2009 (janeiro a abril): a Equipe Paraná percorreu $4.200 \mathrm{~km}$ para realizar inquéritos em Minas Gerais e mais $3.540 \mathrm{~km}$ para documentar o Chuí e alguns pontos do Rio Grande do Sul e de Santa Catarina; a Equipe Bahia teve de vencer $3.700 \mathrm{~km}$ de estrada para fazer as gravações de cidades do Sul da Bahia e do Norte de Minas Gerais, $2.200 \mathrm{~km}$ para duas localidades no interior de Pernambuco e $680 \mathrm{~km}$ para duas no interior do Rio de Janeiro; a Equipe Nordeste documentou duas localidades, uma no Ceará e outra no Rio Grande do Norte e, para isso, viajou 650 km; a Equipe Rio Grande do Sul deslocou-se por $1.190 \mathrm{~km}$ para realizar os inquéritos em duas localidades; e a Equipe Mato Grosso do Sul, para avançar três localidades e quase concluir a documentação do Estado de Goiás, percorreu $4.384 \mathrm{~km}$. Se se somam esses quilômetros percorridos, com eles se pode atingir $50 \%$ da circunferência da terra, na sua parte mais ampla, na linha do equador $(40.070 \mathrm{~km})$. Assim, neste começo do ano, o Projeto ALiB deu metade da volta ao mundo!

Se o espaço exige esforço para ser desbravado, o tempo conspira, sempre, contra o pesquisador, sobretudo se entre trabalho e publicação de resultados se interpõem diferentes tipos de dificuldades a serem vencidas, desde as próprias à análise e exegese dos dados àquelas que dizem respeito ao financiamento da publicação. 
O Projeto ALiB tem as suas raízes plantadas em final de 1996. Em 2001, realiza-se a gravação dos inquéritos referentes ao primeiro ponto da rede documentado - ponto 126 - Quirinópolis (GO). Em começos de 2009, a documentação de dados encontrase integralmente concluída em oito estados e iniciada em todos os demais, o que alcança, no cômputo geral, o percentual de $70 \%$ das 250 localidades que integram a rede de pontos. A isso se acrescem o tratamento dos dados-catalogação, cópia, arquivamento, transcrição grafemática e fonética -, a análise dos materiais com vistas à publicação de resultados e a preparação dos primeiros volumes. As referências no tempo parecem evidenciar certo alongamento da pesquisa, mas, se equacionamos esse tempo ao espaço e, sobretudo, à dificuldade de financiamento sistemático e continuado que assegure a realização do trabalho de campo com tranqüilidade e segurança, vamos ver que o saldo é altamente positivo.

A tudo isso se acrescenta um conjunto de comportamentos metodológicos, referentes à ampliação de parâmetros a considerar - a introdução de princípios pluridimensionais - que o tratamento moderno da Geolinguística está a exigir e que demanda do pesquisador acuidade na utilização e implementação, pois, como assinalam Thun e Radtke (1996, p. 30), "la geolingüística moderna se encuentra en vías de transformarse en una verdadera ciencia de la variación en el sentido del término griego 'diálektos'."

Assim, a ampliação de parâmetros a serem tomados como referência envolve tempo, custo, dimensões da área em investigação, e, como afirmam logo a seguir esses mesmos autores, "La ampliación más frecuente se realiza a partir de la combinación del parámetro diatópico con el diastrático y el diageneracional" (THUN; RADTKE, 1996, p. 31).

Pensando-se nesses dois parâmetros - diastrático e diageracional -, vê-se evidenciar, de forma clara, a importância de serem considerados. Sem se perseguir uma ilustração ampla, procura-se mostrar, de forma exemplificativa, a validade da consideração da variação diastrática, trazendo um caso examinado por Zágari (2005). Trata-se da realização do ditongo ou da sua 
simplificação em palavras como liquidação. $\mathrm{O}$ autor mostra, e ilustra com mapas linguísticos de Minas Gerais que integram o capítulo escrito, que a realização com ditongo cede lugar à realização monotongada, explicando (2005, p. 57-58):

[...] pode-se conjecturar que, num período $1 \mathrm{~A},[\mathrm{kw}]$ era falado por imensa maioria entre pessoas de elevado nível escolar e pouco difundido entre aquelas de baixa escolaridade; pouco a pouco, $[\mathrm{k}]$ foi ampliando o seu espaço na classe mais baixa e penetrando, fortemente, na classe de escolaridade maior (período 1B) e, com certeza, atingindo outros vocábulos que, até então, não tinham sido pegos pela regra (período $1 \mathrm{C)}$.

O parâmetro diageracional, de outra parte, tem-se afigurado de relevância na descrição dos percursos da língua e na configuração das mudanças que se esboçam a cada dia, o que levou Thun e Radtke (1998, p. 32) a afirmarem:

Al combinar el primer parámetro [o diageracional] con el diatópico, la geolingüística satisface su vieja aspiración de hacer visible la diacronía en los mapas diatópicos. Si presuponemos un cartografiado claro, la variación diageneracional muestra el 'tiempo visible' porque representa la convivencia de generaciones.

A evocação de alguns aspectos da moderna metodologia geolinguística vem para mostrar a dimensão da "batalha" que tem a travar o Projeto Atlas Linguístico do Brasil na consecução de seus objetos e na concretização do desejado: um atlas linguístico do Brasil que, ao se situar na chamada nova fase da dialectologia brasileira, venha a contribuir para o melhor conhecimento e para construção da socio-história do português do Brasil, permitindo, assim, que se vislumbre a contribuição efetiva para o conhecimento da diversidade e para o seu equacionamento ao ensino e ao respeito ao direito à diversidade de usos. 


\section{Apresentando o ALiB}

Iniciado em 1996, por ocasião do Seminário Nacional Caminhos e Perspectivas para a Geolingüística no Brasil, realizado no Instituto de Letras da UFBA, em Salvador, o Projeto ALiB é, desde então, coordenado por um Comitê Nacional, inicialmente constituído por seis pesquisadores, ${ }^{1}$ dos quais cinco representavam os atlas linguísticos brasileiros já publicados ${ }^{2}$ e um, os atlas, na época, em andamento.

Atualmente, o Comitê Nacional responsável pelo Projeto ALiB ampliou-se, integrando oito pesquisadores: Suzana Alice Marcelino Cardoso (UFBA), Presidente; Jacyra Andrade Mota (UFBA), Diretora Executiva; Abdelhak Razky (UFPA), Ana Paula Antunes Rocha (UFOP), Aparecida Negri Isquerdo (UFMS), Maria do Socorro Silva de Aragão (UFPB/UFC), Mário Roberto Lobuglio Zágari (UFJF), Vanderci de Andrade Aguilera (UEL), Diretores Científicos.

O Projeto ALiB foi previsto para se desenvolver em quatro grandes etapas, tendo o Comitê Nacional definido, entre 1996 e 2002, em reuniões periódicas, ${ }^{3}$ os princípios metodológicos a serem

\footnotetext{
${ }^{1}$ Participaram do Comitê Nacional, em 1996, os pesquisadores: Suzana Cardoso (UFBA), Jacyra Mota (UFBA), Maria do Socorro Aragão (UFPB/UFC), Vanderci Aguilera (UEL), Mário Roberto Zágari (UFJF) e Walter Koch (UFRGS), este último falecido em fevereiro de 2008.

${ }^{2}$ A Geolinguística brasileira contava, à época do surgimento do Projeto $\mathrm{ALiB}$, com a publicação de cinco atlas - o Atlas Prévio dos Falares Baianos (APFB), publicado em 1963, o Esboço para um atlas lingüistico de Minas Gerais (EALMG), em 1977; o Atlas Lingüistico da Paraíba (ALPB), em 1984; o Atlas Lingüístico de Sergipe, em 1987; o Atlas Lingüistico do Paraná (ALPR), em 1994 -, encontrando-se em elaboração alguns outros.

${ }^{3}$ Realizaram-se, até o presente, 27 reuniões nacionais do Comitê, em diferentes cidades brasileiras, e uma delas, a XXV, em Montevidéu, por ocasião do XV Congresso da ALFAL, algumas abertas a outros pesquisadores. Além das reuniões nacionais, realizaram-se, também, seis Workshops para a discussão do andamento da pesquisa, revisão da metodologia e fixação de metas.
} 
seguidos, fixado o perfil e o número de informantes, a rede de pontos e os tipos de questionário a serem utilizados na constituição do corpus, como se apresenta a seguir.

\section{Os informantes}

Como um projeto que visava a pluridimensionalidade de parâmetros, previu-se, como perfil para os informantes do ALiB, a distribuição por gênero, faixa etária e escolaridade, tendo-se afastado, portanto, daquele modelo tradicional, seguido pela Geolinguística desde o final do século XIX, em que os informantes eram identificados como NORM (nonmobile, older, rural, male), de acordo com Chambers e Trudgill (1994, p. 57), ou, em versão portuguesa, como HARAS (homem, adulto, rurícola, analfabeto e sedentário), na proposta de Zágari (2005, p. 52).

Assim, os 1.100 informantes previstos distribuem-se equitativamente pelos dois gêneros, por duas faixas etárias - uma de 18 a 30 anos, outra de 50 a 65 anos - e por dois graus de escolaridade - fundamental incompleto e universitário completo -, fornecendo dados para a consideração das dimensões diagenérica, diageracional e diastrática.

Para fazer face às dimensões continentais do País e tornar o projeto viável, foi necessário limitar a oito o número de informantes, nas capitais de Estado, e a quatro, nas demais cidades, e a se reduzirem a duas as faixas etárias dos informantes, desprezandose a intermediária, entre 30 e 50 anos, apesar da importância que se atribui, hoje, a essa faixa, em estudos de natureza sociolinguística, a partir da observação de seu comportamento, em determinadas comunidades, sensível ao prestígio atribuído às variantes e preocupado com uma norma mais próxima da considerada ideal ou culta.

Em função dos objetivos do Projeto ALiB, não se introduziu a variação diatópico-cinética a que se refere Thun (1998, p. 375), a propósito dos parâmetros considerados no Atlas Lingüístico Diatópico y Diastrático del Uruguay ( $A D D U$ ), preferindo indivíduos demograficamente estáveis. Nada obstante, em vista dos 
importantes movimentos migratórios presentes em algumas regiões brasileiras e da mobilidade natural a que se submete, atualmente, o indivíduo, previu-se, também, a inclusão de informantes que tenham vivido algum tempo fora da localidade, desde que esse afastamento não ultrapassasse $1 / 3$ de sua vida, não se situasse nos primeiros anos de vida, coincidentes com a fase de aquisição da língua, nem nos anos imediatamente anteriores à data da entrevista. Em algumas localidades, formadas com o concurso de indivíduos de outras áreas, foi necessário, ainda, desconsiderar a exigência de pais naturais da mesma localidade ou da mesma área linguística, principalmente para os informantes da $2^{a}$ faixa etária. A especificidade desses informantes, que deverá ser assinalada nas cartas linguísticas, apontará áreas que poderão ser objeto de pesquisas posteriores.

\section{A rede de pontos}

Quanto à rede de pontos, inevitavelmente menos densa do que a dos atlas regionais, caracteriza-se pela inclusão apenas de sedes municipais, distribuídas por toda a extensão territorial, levando-se em conta os limites interestaduais e internacionais, assim como a densidade demográfica de cada região e de cada Estado.

A escolha das localidades considerou dados de povoamento e de desenvolvimento sociopolítico, econômico e cultural de cada área, sem a preferência por localidades isoladas e pouco desenvolvidas, como na Geolinguística identificada como tradicional e, à exceção do Distrito Federal e de Palmas (TO), por serem capitais com poucos anos de fundação, inclui todas as capitais brasileiras.

Foram também avaliadas as redes de pontos dos atlas publicados e a proposta de Nascentes em Bases para a elaboração do atlas lingüístico do Brasil (1958; 1961), incluindo-se as localidades julgadas condizentes com os critérios do Projeto ALiB. 


\section{Os questionários}

Os questionários para a constituição do corpus contemplam os diferentes níveis da língua, subdividindo-se em fonéticofonológico (QFF), semântico-lexical (QSL) e morfossintático (QMS), e contendo, além desses, quatro questões de pragmática, seis perguntas de natureza metalinguística, quatro temas para a documentação de discursos semidirigidos e um texto para leitura.

A diversidade de dados assim obtida possibilita a análise de outra dimensão, a diafásica ou estilística, considerando-se que o informante, ao responder a questões diretamente dirigidas, especialmente no início da entrevista, monitora mais a sua fala, evitando variantes estigmatizadas ou preferindo aquelas a que atribui maior prestígio, atitude não presente, por exemplo, no relato de fatos marcantes de sua vida, quando solicitado, ao final do inquérito, ou em comentários espontâneos, a propósito de alguma questão.

Exemplifica essa variação o trecho a seguir, ouvido de um informante masculino de faixa etária 1 , de nível fundamental, de Recife, em que a variante africada palatal, no vocábulo muito ocorre, espontaneamente, em comentário à questão referente a abóbora (QFF 032), e não na questão elaborada para a obtenção daquele vocábulo (QFF 077):

\section{Questão 032}

INQ. - Como é que se chama aquilo que dá no chão, grande (mímica), com uma casca grossa vermelho-amarelada por dentro e que se cozinha para comer, para fazer doce?

INF. - É jirimum. Tem a casca amarela e por dento ele é vermelho.

INQ. - Aqui tem muito?

INF. - Tem, tem mun [t $\left.\int\right]$ o jirimum.

\section{Questão 077}

INQ. - Qual é o contrário de pouco?

INF. - muito ['mũ jtu]. 
Com o objetivo de, na medida do possível, uniformizar a aplicação dos questionários, tornando os resultados intercomparáveis, todas as questões apresentam uma formulação inicial, que pode ser reformulada, quando necessário.

O QFF, com que se inicia o inquérito, contém 159 questões sobre fatos fônicos e 11 questões de prosódia, destinadas, sobretudo, à delimitação de áreas dialetais, de modo a confirmar ou complementar estudos anteriores, como a conhecida divisão dialetal proposta por Nascentes (1953), com base na realização aberta ou fechada das vogais médias em distribuição pré-acentuada, como em pecado e coração, ${ }^{4}$ e em diferenças entonacionais entre falares do norte e falares do sul. Ao lado de questões desse tipo, incluem-se algumas outras, destinadas à apuração da variação estrática ou geracional, como as que buscam documentar, por um lado, a despalatalização ou iotização da lateral palatal, em formas como mulher e olho ${ }^{5} \mathrm{e}$, por outro, a palatalização da lateral alveolar seguida de /i/, como em família e sandália. ${ }^{6}$

Para a pesquisa no nível semântico-lexical, o QSL consta de 202 itens, que se distribuem por 15 áreas semânticas.

$\mathrm{Na}$ seleção dos temas das questões levam-se em conta variantes documentadas em trabalhos anteriores, principalmente pelo interesse para a identificação de possíveis áreas dialetais, como, por exemplo: as denominações para estrela cadente, na Bahia, em Sergipe e em Minas Gerais, citadas por Cardoso e Ferreira (1994); os nomes de cunho religioso (São João e Santana), documentados, respectivamente, para junho e julho, em Sergipe, analisados por Ferreira e Freitas (1994); as isoléxicas referentes a cerração, chwva de granizo, bola-de-gude, indicadoras da existência de três falares em Minas Gerais - baiano, mineiro e paulista -, como observa Zágari (2005); as isoléxicas referentes a beija-flor e cuitelo, onda e maré, camomila e maşanilha, urubu e corvo, banana filipe e inconha, que, no Atlas Lingüistico do Paraná (AGUILERA, 1994), distinguem áreas mais antigas e

\footnotetext{
${ }^{4}$ Temas das questões 109 e 119 do QFF, respectivamente.

${ }^{5}$ Tema das questões 112 e 129 do QFF, respectivamente.

${ }^{6}$ Tema das questões 130 e 140 do QFF, respectivamente.
} 
mais novas, confirmando as "três ondas povoadoras" na história da ocupação do Paraná, a que se refere a autora em sua Apresentação (AGUILERA, 1996, p. 7).

Considerando-se o objetivo de fornecer uma macrovisão da realidade linguística brasileira, no tocante à língua portuguesa, não se priorizam, no QSL, denominações referentes a atividades específicas de determinadas regiões, pouco documentadas ou desconhecidas em outras áreas do País, sejam manifestações culturais como o bumba-meu-boi, no Nordeste, os rodeios sertanejos, a festa da uva, na Região Sul; sejam manifestações religiosas como as de origem africana, na Bahia e em alguns outros Estados; sejam cultivos característicos de cada região.

O QMS, com 49 questões, visa a documentar, ao lado da variação diatópica, como a presença ou ausência do artigo diante de nome próprio e o uso de tu ou você como pronomes pessoais de segunda pessoa, ${ }^{7}$ também a variação estrática entre indivíduos de escolaridade fundamental e de nível universitário, contendo, por exemplo, questões dirigidas à obtenção de formas flexionais nominais (plurais de pão, degrau, chapéu, olbo) ou verbais $\left(1^{a}\right.$ pessoa do indicativo presente do verbo caber, $3^{a}$ pessoa do perfeito do indicativo do verbo trazer). ${ }^{8}$

Os quatro temas para a obtenção de discursos mais espontâneos buscam o registro de um relato pessoal sobre acontecimento marcante na vida do indivíduo, um comentário sobre programas de televisão, a descrição da atividade desenvolvida pelo informante e um relato não pessoal.

No primeiro caso, registram-se, em geral, relatos feitos com emoção sobre mortes na família, encontros e desencontros amorosos, relações familiares, nos quais o falante deixa, inteiramente, de controlar o seu desempenho linguístico, fixandose no fato relatado, como se verifica, por exemplo, no trecho a seguir, registrado ao informante de faixa etária 2 , de escolaridade fundamental, em Recife:

\footnotetext{
${ }^{7}$ Temas das questões 1, 2, 24 e 25 do QMS, respectivamente.

${ }^{8}$ Temas das questões 10 a 20; 36 e 41 do QMS, respectivamente.
} 
A gente cum aquele... aquele namorico de... adolescentezinho, se conheceu no carnaval [...] e... brincamos os três dia de carnaval. Depois daí, a gente nunca mais se viu. [...]. E então, passou-se o tempo, uns seis anos... pra sete, né? [...] Daí, quando foi uma certa vez, meu pai adoeceu... teve problema de coração... chegô a falecê, isso no dia três de setembo. No dia três de setembo de setenta e dois, de setenta [...]. Foi e se enterrô no cemitério da Várzea... E o pai dela também morreu no dia três... dia onze de setembro do memo ano, também... coração. Todos dois de coração. E no primero ano de dia de finado, ela foi ao cemitério, né? [...]. Eu cheguei lá no cemitério umas três horas da tarde. Ela estava lá no cemitério e me conheceu... depois de sete anos, sem a gente se vê. Então ela olhô pra mim, sorriu, eu... procurei terra nos pés, num achei, né? (risos). [...]. Morreram da mesma doença, no mesmo mês e todos dois no memo cemitério. [...].Ela saiu cum a cunhada dela, foi embora pra casa... passô aquele tempo... e nós não se vimos outra vez. Mais... um ano e poco, quase dois anos sem se vê. Perdi o contato cum ela, ela perdeu o contato comigo... [...]. Aí a gente começô então se comunicano através de bilete. Aí eu fui... ia pra lá quando largava mais cedo, ia panhá ela lá no trabalho... e sempre me aproximano da casa dela. [...]. Aí foi quando... a gente namoramo dois ano, cum um ano, noivamos... mais um ano, a gente casô.

No relato não pessoal, por outro lado, registra-se, em discurso referido, em estilo direto, a fala de "um outro", com as variantes a ele atribuídas, como, no trecho do informante masculino, de faixa etária 2, nível universitário, de Maceió, contando um assalto sofrido por um amigo:

Aí o cara disse 'Pelo amor de Deus, leve meu carro'. Aí o ladrão disse: 'Que peste qué esse carro véio? Quem é que vai querê esse seu carro véio?' 
As seis questões de natureza metalinguística têm como objetivo o registro do que pensa o informante sobre o modo de falar local, as pessoas que falam "de modo diferente" na localidade ou em outras áreas brasileiras e o falar de épocas anteriores, de modo a fornecer dados para a análise, nas diferentes comunidades, da variação diarreferencial, das crenças sobre a língua, da sensibilidade linguística com relação a variantes estigmatizadas, como observa Aguilera (2008).

Os questionários foram preliminarmente testados em inquéritos experimentais, que se realizaram em diferentes regiões do País, tendo passado por inúmeras revisões até que se chegasse à versão final, publicada em 2001 pela Universidade Estadual de Londrina (UEL). Nada obstante, no decorrer da pesquisa, novos ajustes se fizeram necessários e, como sabem os que trabalham com a recolha de dados empíricos, o questionário ideal só surgirá após a realização de todos os inquéritos, tendo em vista, principalmente, a extensão territorial do País e o grande número de pesquisadores que integram o Projeto ALiB. Muitas dessas dificuldades já as reconhecia Gilliéron, chegando a comentar, como resposta a críticas que lhe foram dirigidas, que "Le questionnaire... pour être sensiblement meilleur, aurait dû être fait après l'enquête" (apud POP, 1950, p. 120).

\section{Considerações finais}

Tendo-se concluído a etapa de constituição do corpus referente às capitais, que deverá compor os primeiros volumes do $\mathrm{ALiB}$, desenvolve-se, atualmente, o tratamento e a análise dessas amostras, ao mesmo tempo em que se dá curso ao registro dos dados linguísticos nas demais localidades da rede, o que corresponde às etapas 2 e 3 do cronograma inicialmente previsto. Já se encontra também em andamento uma quarta etapa, que tem por objetivo a divulgação dos resultados com a apresentação das informações sobre os procedimentos metodológicos adotados (vol. I), dos mapas linguísticos fonéticos (vol. II), semântico-lexicais (vol III) e morfossintáticos (vol. IV), que serão acompanhados de comentários às cartas, como nos atlas considerados de $2^{\mathrm{a}}$ geração, 
e de CDs com amostras dos registros, em cada capital, como nos de $3^{\text {a }}$ geração.

Com o saldo altamente positivo que a construção do ALiB vem propiciando à Geolinguística no Brasil, ressalta-se a implementação de inúmeros trabalhos nessa área - atlas regionais, artigos apresentados em congressos, dissertações e teses de pósgraduação -, alguns diretamente ligados ao Projeto ALiB, o que, segundo Cardoso e Mota (2006), justifica a proposta de uma quarta fase na história da Dialectologia Brasileira, considerando-se encerrada a terceira, anteriormente proposta por Cardoso e Ferreira (1994).

Do ponto de vista metodológico, essa nova fase é marcada também pela incorporação de outros parâmetros, além do diatópico, configurando a Dialectologia Pluridimensional.

E, assim, vem caminhando o Projeto Atlas Linguístico do Brasil: enfrentando o tempo e o espaço, convivendo com as dificuldades inerentes à realização de um trabalho dessa natureza e de tais proporções, mas fiel aos princípios da Geolinguística contemporânea.

\section{Referências}

AGUILERA, Vanderci de Andrade. Crenças e atitudes lingüísticas: quem fala a língua brasileira? In: RONCARATI, Cláudia; ABRAÇADO, Jussara (Orgs.). Português Brasileiro II. Contato lingüístico, heterogeneidade e história. Niterói: EdUFF, 2008. p. 311- 333. EdUel, 1996.

. Atlas Lingüístico do Paraná. Apresentação. Londrina:

Atlas Lingüístico do Paraná-ALPR. Curitiba: Imprensa Oficial do Estado, 1994.

ARAGÃO, Maria do Socorro Silva de; MENEZES, Cleuza Palmeira Bezerra de. Atlas Lingüístico da Paraíba. Brasília: Universidade Federal da Paraíba; CNPq, 1984. 2 v. 
CARDOSO, Suzana; FERREIRA, Carlota. A dialectologia no Brasil. São Paulo: Contexto, 1994.

.; MOTA, Jacyra. Para uma nova divisão dos estudos dialetais brasileiros. In: (Orgs.). Documentos 2 - Projeto Atlas Lingüístico do Brasil. Salvador: Quarteto, 2006. p. $15-26$.

CHAMBERS, Jack K.; TRUDGILL, Peter. La dialectología. Trad. Carmen Morán González. Madrid: Visor Libros, 1994.

ELIZAINCÍN, Adolfo; THUN, Harald. Atlas lingüístico y diatópico del Uruguay. t. I, fasc. A1. Kiel: Westensee, 2000.

FERREIRA, Carlota; FREITAS, Judith. Junho e Julho em Sergipe. In: __ et al. (Orgs.). Diversidade do Português do Brasil. Estudos de dialectologia rural e outros. Salvador: Centro Editorial e Didático da UFBA, 1994. p. 67 - 72.

;___ _ _ MOTA, Jacyra; ANDRADE, Nadja; CARDOSO, Suzana; ROLLEMBERG, Vera; ROSSI, Nelson. Atlas Lingüístico de Sergipe. Salvador: Universidade Federal da Bahia; Fundação Estadual de Cultura de Sergipe, 1987.

GUARNER, Sanchis; CASTELLANO, Rodríguez; OTERO, Aníbal (Coords.). Atlas Lingüístico de la Península Ibérica (ALPI). t. I. Fonética. Madrid: Consejo Superior de Investigaciones Científicas, 1962.

KOCH, Walter; KLASSMANN, Mário S.; ALTENHOFEN, Cléo V. Atlas Lingüístico Etnográfico da Região Sul do Brasil (ALERS). v. I - Introdução. Porto Alegre/Florianópolis/Curitiba: UFRGS/ UFSC/UFPR, 2002.

\section{;____ Atlas Lingüístico Etnográfico da} Região Sul do Brasil (ALERS). v. II - Cartas fonético-fonológicas. Porto Alegre/ Florianópolis/Curitiba: UFRGS/ UFSC/UFPR, 2002. 
NASCENTES, Antenor. Bases para a elaboração do atlas lingüístico do Brasil. Rio de Janeiro: MEC/Casa de Rui Barbosa, v. 2, 1961.

Bases para a elaboração do atlas lingüístico do Brasil. Rio de Janeiro: MEC/Casa de Rui Barbosa, v. 1, 1958.

O linguajar carioca. 2. ed. Rio de Janeiro: Simões, 1953.

POP, Sever. La dialectologie. Aperçu historique et méthodes d'enquêtes linguistiques. Louvain: Chez l'Auteur; Gembloux, Duculot, 1950. v. 1 e 2.

RIBEIRO, José; ZÁGARI, Mário; PASSINI, José; GAIO, Antônio. Esboço de um atlas lingüístico de Minas Gerais (EALMG). I. Rio de Janeiro: Fundação Casa de Rui Barbosa; Universidade Federal de Juiz de Fora, 1977.

ROSSI, Nelson; ISENSEE, Dinah; FERREIRA, Carlota. Atlas Prévio dos Falares Baianos. Rio de Janeiro: Ministério de Educação e Cultura; Instituto Nacional do Livro, 1963.

THUN, Harald. La géographie linguistique romane à la fin du XX siècle. In: CONGRÈS INTERNATIONAL DE LINGUISTIQUE ET DE PHILOLOGIE ROMANES, 22., Bruxelles, 1998. Actes... Tübingen: Max Niemeyer, 2000. p. 367-388. v. III.

.; RADTKE, Edgar. Nuevos caminos de la Geolingǘstica románica. Un balance In: (Orgs.) Neue Wege der Romanischen Geolinguistik. Akten des Symposiums zur empirischen Dialektologie. (Heidelberg/Mainz, 21-24.10.1991). Kiel: Westensee-Verlag. 1996. p. 25-49.

ZÁGARI, Mário Roberto. Os falares mineiros: esboço de um Atlas Lingüístico de Minas Gerais. In: AGUILERA, Vanderci de Andrade (Org.). A Geolingüística no Brasil: trilhas seguidas, caminhos a percorrer. Londrina: Eduel, 2005. p. 45-72. 